\title{
Endovascular treatment of right-sided subclavian artery aneurysm in a congenitally malformed aortic arch
}

Gabriele lannelli, MD, ${ }^{a}$ Luigi Di Tommaso, MD, ${ }^{a}$ Mario Monaco, MD, ${ }^{a}$ and

Federico Piscione, $\mathrm{MD}^{\mathrm{b}}$ Naples, Italy

$\mathrm{E}$ ncouraging results obtained with endovascular treatment of subclavian artery aneurysms (SAAs) ${ }^{1}$ led us to use this technique as an alternative to conventional operation in a young female patient with an intrathoracic SAA on the right side complicated by a left-sided cervical aortic arch and agenesis of the left common carotid and vertebral arteries.

\section{Clinical Summary}

A pulsatile mass was detected in a 38-year-old woman during an echocardiographic assessment of the thyroid. Computed tomographic (CT) scanning showed a 14-mm left-sided cervical aortic arch at the T2 level, a 36-mm enlargement of the ascending aorta, and a normal-sized descending aorta $(25 \mathrm{~mm})$. An angiographic study confirmed the presence of a saccular aneurysm of the right

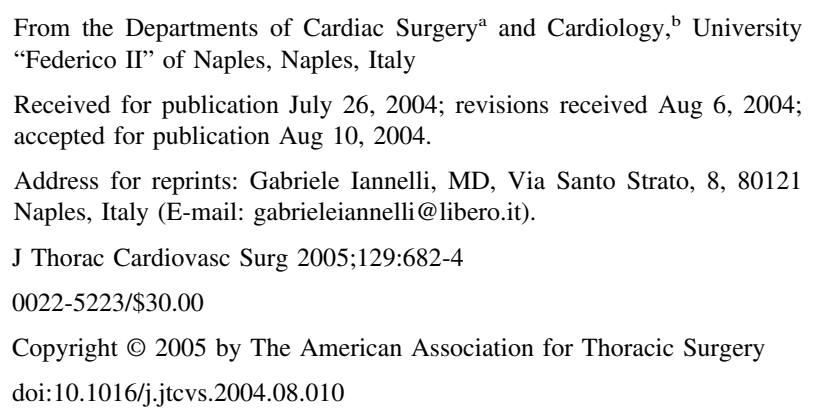

subclavian artery with a broad neck, agenesis of the left carotid artery, and narrowing of

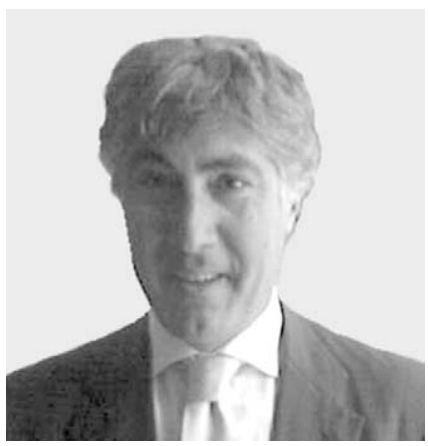

Dr Iannelli the aortic arch (Figure 1). Because of the complexity of the patient's vascular abnormalities, we elected to use an endovascular procedure to treat the right SAA only.

The size of the right subclavian artery was $7 \mathrm{~mm}$, and the aneurysm neck was $20 \mathrm{~mm}$ at the $\mathrm{CT}$ scan: the ideal stent graft length was $40 \mathrm{~mm}$, considering $10 \mathrm{~mm}$ from the aneurysm neck to be a good seal. Otherwise, a more than desirable length could occlude the common carotid artery proximally or the right vertebral artery distally. Fluoroscopic imaging was used throughout the procedure.

General anesthesia was achieved, the right brachial artery was exposed by means of a surgical procedure, and a $12 \mathrm{~F}$ introducer was inserted into the vessel. A $6 \mathrm{~F}$ angiographic pigtail catheter (Cordis Corp, Miami, Fla) was inserted through the femoral artery into the brachiocephalic artery. A 0.035-in Radifocus guidewire M (Terumo Corp, Tokyo, Japan) was inserted through the brachial artery to cross the SAA and to position the stent graft at the proximal end of the subclavian artery. Two stent grafts (Viabahn; W. L. Gore \& Associates, Inc, Flagstaff, Ariz; $8 \mathrm{~mm}$ wide and 25 $\mathrm{mm}$ long) were implanted with the telescope technique, placing the second stent graft to overlap the first distally to obtain the foreseen length.

An angiogram obtained after insertion of the stent grafts showed complete exclusion of the SAA and patency of the right

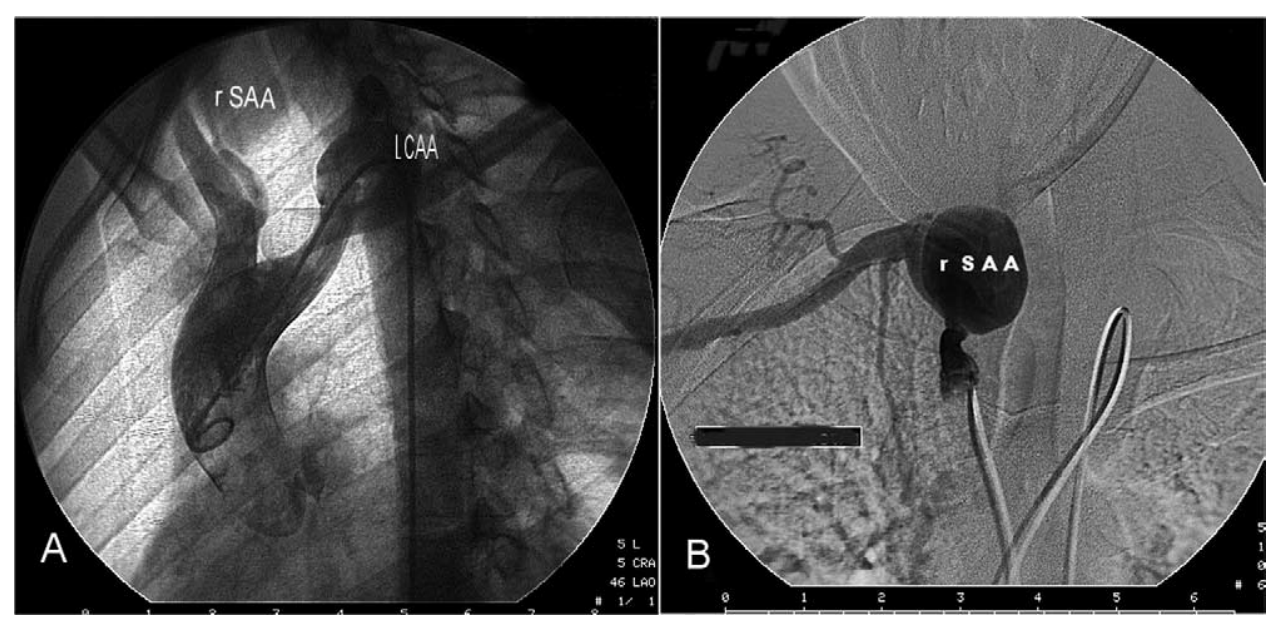

Figure 1. A, Angiogram showing subclavian artery aneurysm on the right side ( $r S A A)$ and cervical aortic arch on the left (LCCA). B, Digital subtraction angiogram of the right-sided subclavian artery aneurysm (rSAA). 


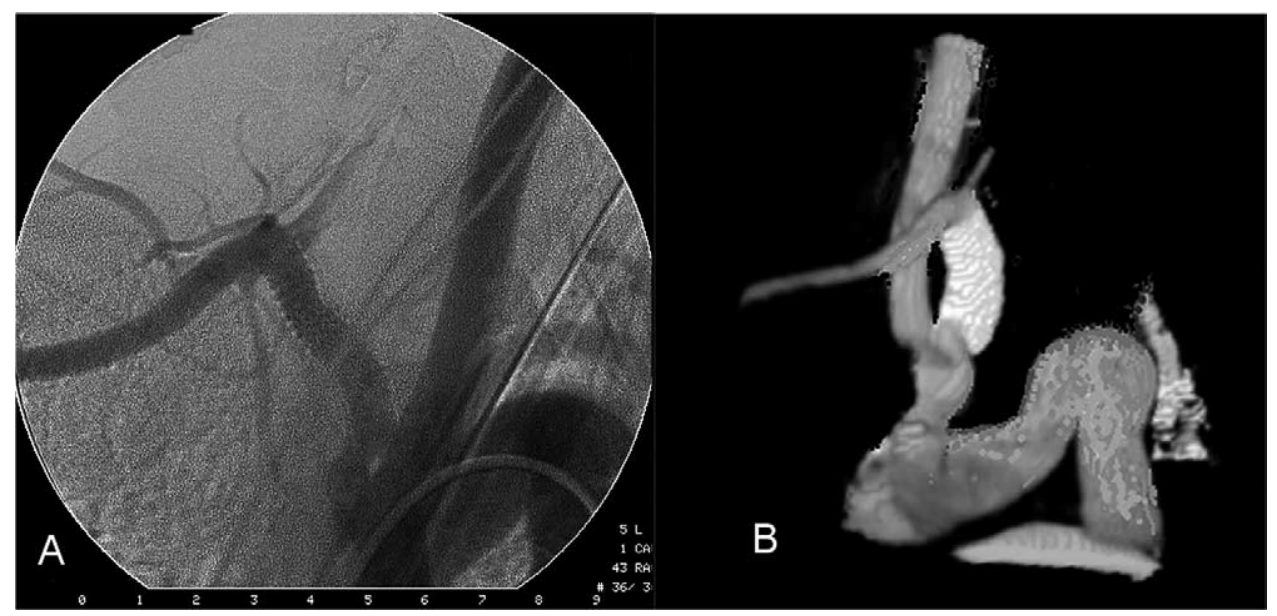

Figure 2. A, Perioperative angiogram of the right subclavian artery after implantation of a stent graft. B, A 6-month 3-dimensional CT follow-up scan.

subclavian and vertebral arteries (Figure 2, A). The patient recovered uneventfully and was discharged from the hospital 3 days after the procedure. At 6 months' follow-up, the patient was doing well, and a CT scan showed aneurysm exclusion and no endoleaks (Figure 2, B)

\section{Discussion}

Of the 6 pairs of embryonic aortic arches that connect the ventral and dorsal portions of the aorta, only the third, fourth, and sixth arches remain recognizable after birth (Figure 3, A). The cervical aortic arch, first described by Reid in 1914, is a rare embryologic malformation caused by nondevelopment of the left-sided fourth embryonic arch and persistence of the third (Figure 3,B). ${ }^{2}$

An aortic arch formed from an embryologic remnant designed to regress might not have normal structural integrity. This characteristic, together with the hemodynamic changes in the tortuous cervical aortic arch, can create conditions favorable for formation of an aneurysm. ${ }^{3}$

Surgical treatment of SAAs is necessary because of the high risk of rupture of large aneurysms and of embolization or thrombosis in smaller aneurysms. ${ }^{4}$ Only a few cases of congenital aneurysm of the major supraortic branches and cervical aortic arch have been reported. ${ }^{5}$

The type of complex pathology found in our patient led to an in-depth analysis of the most appropriate surgical strategy, either conventional or endovascular, both of which required prosthetic material. The patient was unwilling to undergo open surgery for cosmetic reasons, and moreover, the traditional surgical approach, which would have involved a median sternotomy with a supraclavicolar extension, would entail a considerable risk of damage to the cerebral blood flow caused by the reduction of collateral arterial supply and the very close localization to the aneurysm of the carotid and vertebral right arteries.

Endovascular surgery, on the other hand, was considered feasible for the presence of a satisfactory landing zone, measuring proximally $1.5 \mathrm{~cm}$ from the right common carotid artery and distally $1.0 \mathrm{~cm}$ from the right vertebral artery. Use of the endovascular approach in our patient allowed us to comply with the
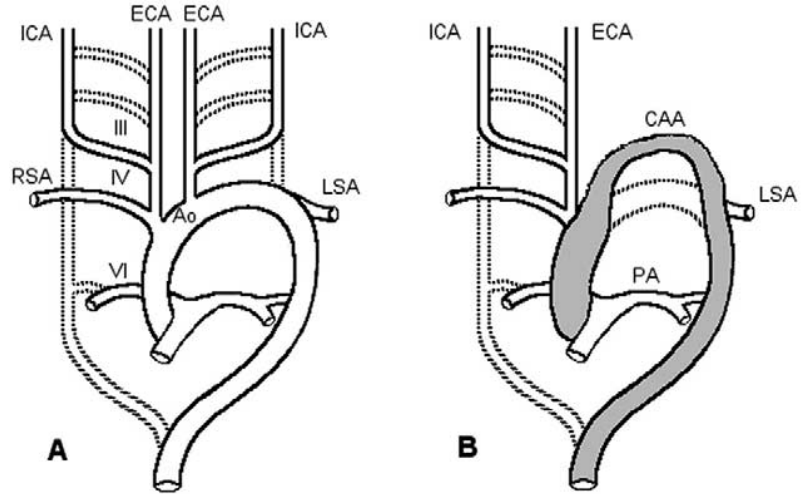

Figure 3. Normal and abnormal development of the aorta. A, Normal development of the 6 pairs of embryonic aortic arches. B, Abnormal development of the aorta and side branches in our patient. ICA, Internal carotid artery; ECA, external carotid artery; $R S A$, right subclavian artery; $L S A$, left subclavian artery; $A o$, thoracic aorta; III, third embryonic aortic arch; IV, fourth embryonic aortic arch; VI, sixth embryonic aortic arch; $P A$, pulmonary artery; CAA, cervical aortic arch.

patient's requests regarding cosmetic results. In addition, use of endovascular treatment does not preclude subsequent use of conventional surgery if required because of unsatisfactory results or deterioration of materials used.

Successful use of endovascular grafts in other locations and in our experience suggests that endovascular surgery might be a safe and reliable treatment for some very rare vascular disorders.

We thank Mr Lucio Riccardi for his contribution to this effort.

\section{References}

1. Iannelli G, Piscione F, Di Tommaso L, Monaco M, Chiariello M, Spampinato N. Thoracic aortic emergencies: impact of endovascular surgery. Ann Thorac Surg. 2004;77:591-6. 
2. Pearson GD, Kan JS, Neill CA, Misgley FM, Gardner TJ, Hougen TJ. Cervical aortic arch with aneurysm formation. Am J Cardiol. 1997;79: 112-4.

3. Farsak B, Yilmaz M, Kaplan S, Boke E. Cervical aortic arch with aneurysm formation. Eur J Cardiothorac Surg. 1998;14:437-9.
4. Davidovic LB, Markovic DM, Pejkic SD, Kovacevic NS, Colic MM, Doric PM. Subclavian artery aneurysms. Asian J Surg. 2003;26:7-11.

5. Tsukamoto O, Seto S, Moriya M, Yano K. Left cervical aortic arch associated with aortic aneurysm and coartation, and branch artery aneurysm: a case report and review. Angiology. 2003;54:257-60.

\title{
A successful total cavopulmonary connection conversion 13 years after an anatomic repair for tricuspid atresia IIc with severe pulmonary resistance
}

\author{
Koichi Sughimoto, MD, Hiromi Kurosawa, MD, Toshiharu Shin'oka, MD, Masayoshi Nagatsu, MD,
} Shigehiro Morishima, MD, and Takahiko Sakamoto, MD, Tokyo, Japan.

$\mathrm{H}$ igh pulmonary artery resistance $(\mathrm{Rp})$ is one of the risk factors for Fontan completion. Although appropriate pulmonary artery banding (PAB) might decrease the pulmonary artery pressure (PAP), there are some patients who are unable to undergo the Fontan procedure because of high Rp. Anatomic repair with pulmonary autograft for the Björk procedure is one of the options for those patients. On the other hand, total cavopulmonary connection (TCPC) conversion is currently performed for patients with arrythmia or intra-atrial thrombus after atriopulmonary connected Fontan circulation. ${ }^{1-3}$ We recently had a successful experience with extracardiac TCPC conversion after anatomic repair.

\section{Clinical Summary}

A 4-year-old boy with tricuspid atresia (TA) IIc and a ventricular septal defect had undergone an anatomic repair consisting of Jatene, Rastelli, and Björk procedures in 1989. PAB at 19 days of age, a Blalock-Hanlon procedure at 10 months of age, and right pulmonary artery (PA) angioplasty, digital septostomy, and re$\mathrm{PAB}$ at 2 years and 4 months of age had been performed previously. Preoperative catheterization data showed a high mean PAP of $20 \mathrm{~mm} \mathrm{Hg}$, a PA index of 366, a pulmonary artery resistance (Rp) of 5.7 units, and a right ventricular end-diastolic volume of $49 \%$ of the normal value (Table 1). These data suggested that the Fontan procedure was unfavorable at that time, and therefore anatomic repair was planned. The original aorta was implanted between the right atrium (RA) and the right ventricle (RV). The

From the Department of Cardiovascular Surgery, The Heart Institute of Japan, Tokyo Women's Medical University, Tokyo, Japan.

Received for publication May 8, 2004; revisions received June 23, 2004; accepted for publication June 28, 2004.

Address for reprints: Hiromi Kurosawa, MD, Department of Cardiovascular Surgery, The Heart Institute of Japan, Tokyo Women's Medical University, Tokyo, Japan, 8-1 Kawada-cho, Shinjuku-ku, Tokyo, 162-8666, Japan (E-mail: kurosawa@hij.twmu.ac.jp).

J Thorac Cardiovasc Surg 2005;129:684-5

$0022-5223 / \$ 30.00$

Copyright $\odot 2005$ by The American Association for Thoracic Surgery doi:10.1016/j.jtcvs.2004.06.047
TABLE 1. Cardiac catheterization data

\begin{tabular}{lrcccc}
\hline & $\begin{array}{c}\text { PAP } \\
\text { (mm Hg) }\end{array}$ & $\begin{array}{c}\text { PA } \\
\text { index }\end{array}$ & $\begin{array}{c}\text { Rp (dyne } \cdot \mathbf{s} \\
\left.\cdot \mathbf{c m}^{-5}\right)\end{array}$ & $\begin{array}{c}\text { RVEDV } \\
\text { (\% of } \\
\text { normal) }\end{array}$ & $\begin{array}{c}\text { LVEDV } \\
\text { (\%ormal) }\end{array}$ \\
\hline nefore AP & $\begin{array}{r}(20) \\
\text { normal }\end{array}$ \\
After AP & $20 / 13(15)$ & & 5.7 & 49 & 229 \\
Before & $18 / 10(14)$ & 138 & 1.4 & 45 & 196 \\
TCPC-c & & & 1.8 & 73 & 113 \\
\end{tabular}

$\overline{P A P}$, Pulmonary artery pressure; $P A$, pulmonary artery; $R p$, pulmonary artery resistance; RVEDV, right ventricular end-diastolic volume; $L V E D V$, left ventricular end-diastolic volume; $A P$, anatomic repair; $T C P C-C$, total cavopulmonary connection conversion.

coronary arteries (Shaher 1) were translocated to the original PA trunk. After repositioning of the PA as the neoaorta with the Lecompte modification, the RV outflow tract was repaired with a tricuspid Xenomedica conduit (22 mm; Xenomedica AG, Luzern, Switzerland) and connected to the main PA. Jatene, Rastelli, and Björk procedures were completed (Figures 1 and 2). The final central venous pressure (CVP) in the intensive care unit was 19 $\mathrm{mm} \mathrm{Hg}$.

The postoperative course was uneventful. However, repeated atrial flutter and ascites have been recognized since the patient was 14 years old, 10 years after the operation. An unsuccessful catheter ablation, the markedly enlarged RA, and an increased CVP indicated the need for TCPC conversion at 18 years of age, 13 years after the anatomic repair.

After establishment of cardiopulmonary bypass, a bidirectional Glenn (BDG) anastomosis was performed initially. Afterward, the aortic autograft was removed, and the RA-RV route was reconstructed with an enlarged RA wall so that only the coronary venous blood passed through the RV to the PA. Subsequently, the extracardiac TCPC conversion was completed with an interposition of the expanded polytetrafluoroethylene graft $(24 \mathrm{~mm})$ between the right PA and the inferior vena cava. The maze procedure was not performed because of extremely dense epicardial adhesion. The CVP decreased gradually to $13 \mathrm{~mm} \mathrm{Hg}$ in the intensive care unit, and the atrial flutter disappeared entirely at the time of discharge. 